http://dx.doi.org/10.18232/20073496.1259

Artículos

\title{
El mercado musical italiano en Argentina, 1895-1914
}

\section{The Italian musical market in Argentina, 1895-1914}

\author{
Mariela Ceva ${ }^{1,2, ~ * ~(D) ~ 0000-0002-3454-2196 ~}$ \\ ${ }^{1}$ Centro de Investigaciones Sociales, Instituto de Desarrollo Económico y Social, Consejo Nacional de Investigaciones Científicas y \\ Técnicas, Buenos Aires, Argentina. \\ ${ }^{2}$ Universidad Nacional de Luján, Luján, Argentina. \\ *Correspondencia: mariela.ceva@gmail.com
}

Resumen. El artículo tiene por objetivo estudiar un mercado particular y heterogéneo, el de los cantantes de ópera que circulaban por los teatros de Argentina entre 1895 y 1914. La hipótesis de investigación es que, en sintonía con la expansión y consolidación de otros mercados, en el mercado musical las decisiones empresariales, la complementación de las temporadas entre Sudamérica y Europa, la aceleración en las comunicaciones, la publicidad y marketing, y la profesionalización de las giras, permitieron la consolidación de un mercado de consumo operístico. El trabajo se divide en tres partes: la primera sobre la geografía teatral y el origen de los músicos; la segunda sobre los actores que contribuían a dar forma a las estructuras formales e informales de gestión. En el cruce de ambas dimensiones se encuentran las redes de relaciones sobre las que profundizaremos en un tercer punto.

Palabras clave: migración; mercado de trabajo; historia social; opera; redes sociales.

Abstract. The article aims to study a peculiar and heterogeneous market, that of opera singers, who circulated in the theaters of Argentina in the years from 1895 to 1914. The research hypothesis is that, in tune with the expansion and consolidation of other markets, in the musical business decisions; the complementation of the seasons between South America and Europe; acceleration in communications; advertising and

CÓMO CITAR: Ceva, M. (2022). El mercado musical italiano en Argentina entre 1895 y 1914. América Latina en la Historia Económica, 29(2), 1-23. DOI: 10.18232/20073496.1259 
marketing; and the professionalization of the tours, allowed the consolidation of an operatic consumer market. The work is divided into three parts: a first on the theatrical geography and the origin of the musicians; a second on the actors who contributed to shaping the formal and informal management structures. At the crossroads of both dimensions are the networks of relationships on which we will deepen into a third point.

Key words: migration; labor market; social history; opera; social networks.

JEL: N76; N86; N96.

Recibido: 7 de octubre de 2020.

Aceptado: 9 de septiembre de 2021.

Publicado: 14 de febrero de 2022.

Organismo patrocinador: Investigación realizada en el marco del pict núm. 2015-3831, Historia y patrimonio de la Argentina moderna. Inmigración, transferencia y readaptación de saberes en las dimensiones simbólicas y materiales de los teatros del litoral rioplatense y su conservación, FONGYT, 2016-2021.

Agradecimiento: Agradezco a Alicia Bernasconi por la información proporcionada de la Lista de vapores arribados al puerto de Buenos Aires [Base de datos].

\section{INTRODUCCIÓN}

Los estudios migratorios han abordado minuciosamente las diversas aristas de los procesos de movilidad. Quizá uno sobre el que más se ha profundizado sea el del mercado de trabajo. Sin embargo, dentro de ellos se ha priorizado a los trabajadores no calificados o semicalificados en desmedro de los trabajadores más calificados, por ejemplo, los músicos. Asimismo, en las escasas investigaciones en las que el tema ha sido abordado, la mirada se ha centrado en un análisis biográfico $^{1}$ de algunos de ellos sin considerar el funcionamiento del sector propiamente dicho. En esta oportunidad nos centraremos en reconstruir un mercado particular y heterogéneo como es el de los cantantes de ópera en los teatros de Argentina entre 1895 y 1914.

Es sabido que el tema del mercado de trabajo presenta dos problemas centrales. Uno de ellos se relaciona con las características estructurales y de funcionamiento del mercado específico que se analice. Otro se vincula a la presencia o no de movilidad social y espacial que afecta a esos trabajadores. Sobre ambos puntos existen numerosos debates teóricos, ${ }^{2}$ en nuestro caso el análisis pone el acento en remarcar la necesidad de estudiarlos en la interrelación que surge de ambos. Para ello se deben considerar algunas cuestiones de base, por ejemplo, profundizar en los cambios que acontecen en el ambiente laboral, esto es visualizar la rapidez de la expansión del mercado y el número de trabajadores que incluían los sectores que se están analizando. Pero además es preciso identificar que la fragilidad y la desigualdad en el mundo musical es un rasgo natural y que el mismo se ve potenciado según los sectores y las regiones sobre las que se profundice. Para ello el presente artículo se divide en tres partes: la primera versa sobre la geografía teatral argentina; en la segunda se profundiza en la formación del mercado y del público, es decir, en los actores que actuaban en ese mercado musical y que contribuían a dar forma a las estructuras formales e informales de gestión; y en la tercera parte se analizan las redes de relaciones que sostienen la trama del mundo musical en formación.

${ }^{1}$ Sobre las formas y modos de difusión de los cantantes italianos líricos en Argentina, véase Cetrángolo (2015). Sobre investigaciones desde las trayectorias de cantantes italianas en Argentina, véase Ceva (2020b).

${ }^{2}$ Sobre los debates acerca del mercado de trabajo, la movilidad social y espacial, véase Thernstrom (1964). 


\section{LA GEOGRAFÍA TEATRAL ARGENTINA}

Entre finales del siglo XIx e inicios del xx, Argentina evidenció un proceso de transformaciones políticas, económicas, sociales y culturales provocadas, en gran parte, por la migración ultramarina. Su presencia impactó sobre la estructura social, en las formas de organización asistencial y sindical, en la configuración de un renovado y dinámico mercado laboral y también en los lugares de diversión y ocio. La influencia cultural de los grupos extranjeros, sobre todo italianos, que por entonces representaban cerca de la mitad de la población de Buenos Aires, era perceptible en la existencia de numerosos periódicos en idioma extranjero, en libros y revistas de difusión de las colectividades, como también en los festejos conmemorativos que remitían a los países de origen. En un primer momento, las salas de las sociedades de socorros mutuos servían como espacios de reunión y de encuentro ${ }^{3}$ posteriormente, y junto con el crecimiento económico del país, esos lugares también sumaron actividades culturales y se fueron transformando en salas teatrales.

La construcción de teatros en Argentina venía creciendo vertiginosamente desde la segunda mitad del xix. Con base en los Censos Nacionales de Población de Argentina de 1895 y 1914, una muestra preliminar de la cantidad de teatros durante ese periodo muestra ese crecimiento. De hecho, para el censo de 1895 en el territorio argentino había 80 teatros, y para 1914 se censó un total de 557. ${ }^{4}$ Según la información de 1895 (República Argentina, 1895, t. 3, cap. xIV, cuadro I, p. 490), ${ }^{5}$ se puede observar que $44 \%$ de los teatros se encuentran en la provincia de Buenos Aires, mientras que 25 \% está asentado en la Capital Federal. Luego están las provincias de Santa Fe y Entre Ríos que cuentan con seis salas teatrales cada una y no muy distante aparece Corrientes. Es interesante subrayar que la provincia de Córdoba se encuentra totalmente relegada en números.

Según el Tercer censo nacional de población, en 1914, si solo consideramos los teatros que incluyen el nombre ópera, se observa que son 46 en todo el país, distribuidos muy desigualmente: $36 \%$ se encuentra en la provincia de Buenos Aires y $13 \%$ en la Capital Federal. Un cambio destacable es que la provincia de Entre Ríos tiene más teatros que Santa Fe. Córdoba sigue sin aparecer. De los 46, solo uno declara la ópera como única actividad: el teatro Colón de Buenos Aires. Todos los demás a la ópera agregan, como mínimo, opereta, zarzuela, comedia y drama, y otros (muchos) incorporan cine y atracciones varias. En el caso de la provincia de Santa Fe tiene una gran concentración de teatros en Rosario (cuatro de ópera), uno en la Capital, pero en las demás ciudades solo un par ofrecen operetas y zarzuelas (Bernasconi y Ceva, 2018, p. 181).

Es decir, para este periodo el litoral rioplatense es un polo destacado frente al resto del interior del país. El crecimiento implica que en 20 años los teatros se multiplicaron por tres. ${ }^{6}$ Una forma de exponer más claramente ese aumento es incorporar al análisis la correlación que existía entre el número de teatros y la cantidad de habitantes. El resultado es que para 1895 la provincia de Buenos Aires tenía un teatro por cada 26319 habitantes; la Capital Federal, uno por cada 33192

${ }^{3}$ El surgimiento de asociaciones de socorros mutuos en Argentina respondía a una tendencia nacional vinculada a las necesidades sanitarias, educativas y recreativas de la población recién llegada. Se constituían además en centros de sociabilidad y también generadoras de ámbitos para la cultura, tales como los teatros. Sobre las sociedades de socorros mutuos en Argentina, véase Devoto (2003).

${ }^{4}$ Los datos incluyen todos los tipos de salas identificadas como teatros, independientemente del tipo de espectáculo que en ellas se brindaran.

${ }^{5}$ Se encuentra agregado por región, pero no discrimina entre los diversos tipos de teatros, diferenciación que sí presenta el censo de 1914.

${ }^{6}$ Si se lo compara por ejemplo con Italia, en 1871 había 940 teatros y para 1907 ese número había ascendido a 3000 salas teatrales. 
y el Litoral (Entre Ríos, Santa Fe y Corrientes) tenía un teatro por cada 178630 habitantes. Para el censo de 1914 el progreso se había dado en todas las jurisdicciones. Así, la provincia de Buenos Aires contaba con un teatro para 12017 habitantes; la Capital, uno por cada 10 647, y el litoral uno por cada 45765 pobladores. Si consideramos el conjunto de las provincias seleccionadas y Capital Federal, para 1895 existía un teatro por cada 35624 habitantes, mientras que para 1914 era de un teatro por cada 11604 habitantes. Aún más, si se considera el incremento intercensal medido en porcentaje, el litoral logró incrementar el número de salas teatrales en $74.37 \%$, mientras que la provincia de Buenos Aires lo hizo en 54 \% y la Capital Federal en 67 por ciento.

El crecimiento entre el fin del siglo XIx y la primera década del xx fue exponencial y al mismo tiempo es evidente que esa geografía de los teatros en Argentina supuso una situación de desequilibrio regional, aunque no necesariamente implicó un centralismo exclusivo de Buenos Aires frente al interior, sino una imagen policéntrica, ya que hay varias provincias que concentran reductos significativos (véase mapa 1).

El mapa 1 muestra la distribución de teatros en el territorio nacional; sin embargo, se debe considerar que las características de los teatros diferían notablemente. Según el relevamiento censal, la gran cantidad de salas teatrales tenían cualidades muy disimiles entre sí, se puede identificar que solo siete teatros de ópera, ubicados en territorio nacional, tenían un valor total (entre edificio, terreno e infraestructura) superior a 500000 pesos moneda nacional. Entre ellos tres se encuentran en Santa Fe (Odeón, Opera y Colón); uno en Santiago del Estero (25 de Mayo); uno en Tucumán (Odeón), y el Tres de Febrero de Paraná, en la provincia de Entre Ríos. Algunas características colaboraban para que estas diferenciaciones fueran tan marcadas, por ejemplo, la ubicación del terreno en zona céntrica elevaba el valor total, el uso de luz eléctrica, el número de plateas y la existencia de sanitarios en su interior. ${ }^{7}$ Por supuesto el teatro Colón de Buenos Aires lidera la lista (República Argentina, 1914, pp. 568-575).

Asimismo, este universo presentaba diferencias sustanciales según fueran de gestión municipal o asociativa y, por otro lado, por el tipo de espectáculos ${ }^{8}$ que brindaban, ya fueran de variedades, ${ }^{9}$ ópera o teatro politeama. ${ }^{10}$ Según el censo nacional de 1914 muy pocas eran las salas que dependían del municipio. Desde la segunda mitad del siglo xix las municipalidades, creadas hacia 1876, habían comenzado a actuar sobre diferentes actividades para la vida pública de la población, una de las formas fue intervenir sobre los espacios de diversión, entre ellos las salas teatrales. Generalmente, su acción se limitaba a la construcción, ya que luego la administración era transferida, a través de contratos de alquiler, a empresarios que se encargaban de organizar la agenda cultural anual. La inversión, por parte del municipio, en la construcción de estos espacios suponía una

${ }^{7}$ Sobre las diferencias entre las diferentes salas teatrales desde el punto de vista arquitectónico, véase Grementieri y Shmidt (2019).

${ }^{8}$ En realidad, el término tipo de espectáculo es utilizado en los censos nacionales de 1895 y 1914 y engloba en el mismo ítem dos clasificaciones diferentes: un tipo de espectáculo concreto, es decir, variedades, mientras que otra hace referencia a un tipo de sala teatral como es el caso del politeama.

${ }^{9}$ Como espectáculo de varieté o de variedades se entiende aquel en el que alternan actuaciones musicales, humorísticas y de otra índole.

${ }^{10}$ La palabra politeama hace referencia a polis, muchos; teama, temas. Se aplica a un lugar con amplia capacidad, adaptabilidad y multifuncionalidad que permite la presencia de espectáculos indiferenciados. En Argentina se adoptó el politeama según el modelo italiano. Su uso fue utilizado por primera vez en el teatro de Palermo, Nápoles, Italia, para diferenciarse del teatro de ópera Carlo Felice de Génova. Véase Cavaglieri (2008, p. 137). 


\section{MAPA 1. GEOGRAFÍA TEATRAL ARGENTINA, 1895 y 1914 (TEATROS, CANTIDAD POR AÑO)}

1895

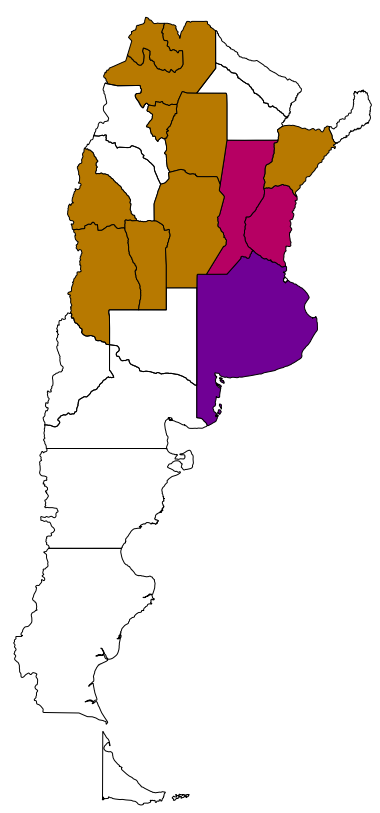

1914

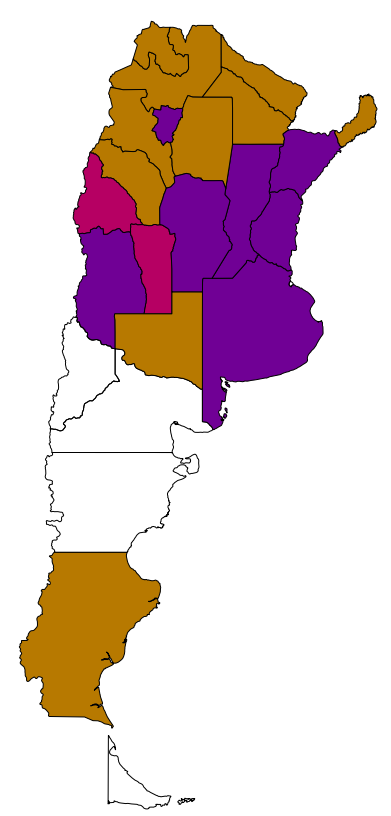

$15-1000$

$6-10$

$1-5$

Fuentes: República Argentina (1895, 1914).

erogación, que acentuaba el déficit -que habitualmente tenían los gobiernos locales-, pero a pesar de ello, y debido a la importancia que significaba contar con un teatro, muchas administraciones emprendían la tarea. Una vez construido se decidía arrendar o alquilar los espacios a particulares.

La gestión privada tenía como protagonista al empresario quien detentaba una responsabilidad productiva (Cavaglieri, 2012, p. 124). Este vínculo comercial entre lo público y lo privado contribuyó a la expansión de un mercado particular que combinaba productos nacionales (teatro nacional y circo criollo) con otros internacionalizados (ópera y opereta). John Rosselli (1992) ha establecido muy tempranamente los cuatro elementos que definen al mercado operístico transatlántico, entre Italia y Sudamérica, en el cual por supuesto se encontraba Argentina. En primer lugar, la confluencia de una demanda y una oferta de trabajadores, es decir, un grupo de cantantes y teatros que ofrecieran espectáculos de diferentes calidades, horarios y exigencias con oportunidades suficientes para satisfacer la demanda. En segundo lugar, la retribución en dinero, esto es lo que permite entrelazar los diversos sectores de un mercado a otro. En tercer lugar, los teatros y los artistas deben estar comunicados, para lo cual requieren de intermediarios. Para facilitar estos 
diálogos entre artistas y empresarios se constituyeron agencias que eliminaban los intermediarios y simplificaban la estructura comunicativa. Por último, los cantantes y los dadores de trabajo requieren contratos basados en reglas conocidas a partir de las cuales se resuelven las disputas entre ambas partes (Giaccometti, 2013, pp. 12-14).

Ciertamente, estas asociaciones comerciales entre capitales públicos y privados requerían fundamentalmente de un espacio material (el teatro); una oferta cultural ampliada (la mayoría de las salas teatrales estaban preparadas para ofrecer desde circo hasta ópera); un público (que en las nuevas ciudades de inicio de siglo era diverso, heterogéneo, nativo y extranjero), y profesionales (músicos, actores, cantantes) y también trabajadores que se vinculaban directamente con la construcción y mantenimiento de esos espacios (escenógrafos y tramoyistas).

\section{LA FORMACIÓN DEL MERCADO. TIPO DE PROFESIONALES, ESPECTÁCULOS Y PÚBLICO}

\section{Algunos números}

El universo de trabajadores y profesionales que se relacionaban con el mercado musical era muy abarcador, según los censos de 1895 y 1914, el crecimiento de todos los rubros vinculados directa o indirectamente a la actividad teatral presenció, durante esos años, un salto considerable, llegando a duplicarse en todas las provincias seleccionadas. Entre las ocupaciones vinculadas a la actividad teatral-musical se encontraban los arquitectos, dibujantes, fotógrafos, escultores, artistas, músicos, y para el Censo de 1914, además de las categorías citadas, se agregan las de artistas pintores y artistas teatrales (véase gráfica 1).

Si consideramos el incremento porcentual entre cada uno de los grupos se destaca un crecimiento abismal en el grupo Otros en la provincia de Buenos Aires, lo que alcanza $2530 \%$. Ese grupo también creció en $352 \%$ en Corrientes, $325 \%$ en Entre Ríos, $230 \%$ en Santa Fe y 174 \% en Capital Federal. Recordemos que aquí se hace referencia a todas las ocupaciones que se vinculaban a los teatros y que su crecimiento claramente se encuentra ligado al despegue económico evidenciado en Argentina del litoral, producto del auge exportador de esos años.

En el caso de los músicos, un primer inconveniente que surge para profundizar en el tema, desde una perspectiva cuantitativa, es que en la categoría música se incluye conjuntamente a los compositores, a los directores y a los cantantes; el segundo problema es que en este grupo la movilidad se encuentra en la base de su vida profesional, por naturaleza la ocupación de los cantantes y músicos se destaca por su carácter itinerante, lo cual implica que músicos que aparecen en una provincia solo estuvieran transitoriamente en ella, al momento en que el censista realizaba la visita. ${ }^{11}$ En cualquier caso, consideramos que una mirada comparativa a partir de los censos de 1895 y de 1914 puede arrojar una primera imagen cuantitativa de su representación en las provincias seleccionadas (véase gráfica 2).

El aumento en el transcurso de 19 años fue cercano a $100 \%$, sin embargo, esto coincide con el crecimiento demográfico general, por lo tanto, su proporción sobre el total de la población se mantiene inalterable. En el caso de los músicos, su presencia durante el año 1895 es más pareja entre la Capital Federal y la provincia de Buenos Aires, mientras que en las provincias del litoral

${ }^{11}$ El tema de la movilidad espacial de los músicos desde una perspectiva cualitativa puede ser abordada desde diferentes fuentes: el seguimiento en la prensa de los avisos de presentaciones teatrales; los afiches de carteleras de los teatros; los recorridos de las compañías, o las memorias escritas por músicos. Sobre acercamientos desde esas otras miradas, véanse Bernasconi y Ceva, (2018, 2020b), Paoletti (2015), Weber, Martinovich y Camerata (2019). 


\section{GRÁFICA 1. OCUPACIONES VINGULADAS A LOS TEATROS (SEGÚN PROVINCIAS, 1895 Y 1914)}

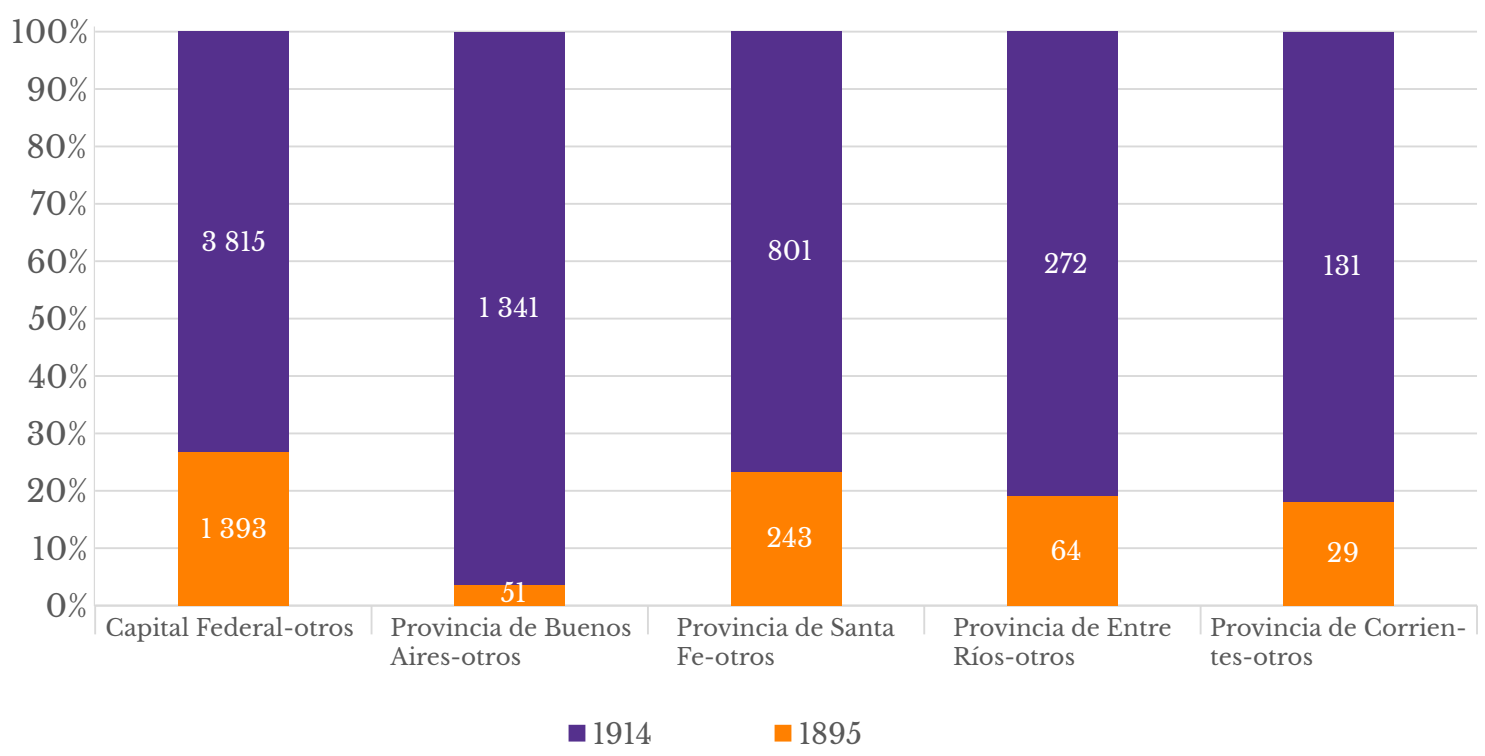

Nota: para 1895 en otros se incluyen arquitectos, dibujantes, fotógrafos, escultores, artistas. Para 1914, además de las categorías citadas, se agregan las de artistas, pintores y artistas teatrales.

Fuentes: República Argentina (1895, 1914).

se destaca Santa Fe, con un predominio de Corrientes sobre Entre Ríos que se diluye para 1914. Para este año, la cantidad en la Capital Federal se ha incrementado en casi $150 \%$ respecto a Buenos Aires. Mientras que en el litoral la situación se ha invertido: Entre Ríos tiene un claro predominio sobre Corrientes. Posiblemente esta situación obedezca al despegue económico y al crecimiento de salas teatrales ocurrido en la provincia de Entre Ríos, durante los primeros años del siglo xx, potenciado por la remodelación del Puerto de Paraná ${ }^{12}$ que permitía una mayor circulación.

Si nos detenemos en el análisis sobre el origen de los músicos, en las provincias seleccionadas, un primer dato que surge es que el componente extranjero para 1895 y para 1914 es aproximadamente de 60 \%. Según el Censo de 1895: 1728 músicos son extranjeros sobre un total de 3 064, para el Censo de 1914, la cantidad de extranjeros es de 1918 sobre un total de 3 317, lo que varía ostensiblemente es su distribución en el territorio. En 1895, Capital Federal es el distrito en el que los extranjeros alcanzan el mayor porcentaje, 44 \% (véase gráfica 3 ).

Asimismo, si consideramos el sexo también existen diferencias regionales: en la provincia de Buenos Aires los argentinos varones ascienden a 426 frente a 178 extranjeros, contrariamente en la Capital Federal, 617 extranjeros destacan sobre 119 nativos. Para 1914 en el caso de la provincia de Buenos Aires la relación entre argentinos y extranjeros se encuentra equiparada y en la capital los extranjeros llegan a duplicar a los argentinos. Si nos detenemos en las mujeres extranjeras para

${ }^{12}$ A inicios del siglo xx se realizaron importantes remodelaciones en el puerto de Paraná. Con el puerto nuevo, la ciudad adquirió un mayor peso en el contexto regional, a ello se sumó la reinauguración de la sala del teatro Tres de Febrero, lo que congregó una gran afluencia de cantantes, véase Ceva (2019). 


\section{GRÁFICA 2. MÚSICOS EN ALGUNAS PROVINCIAS ARGENTINAS, 1895 Y 1914}

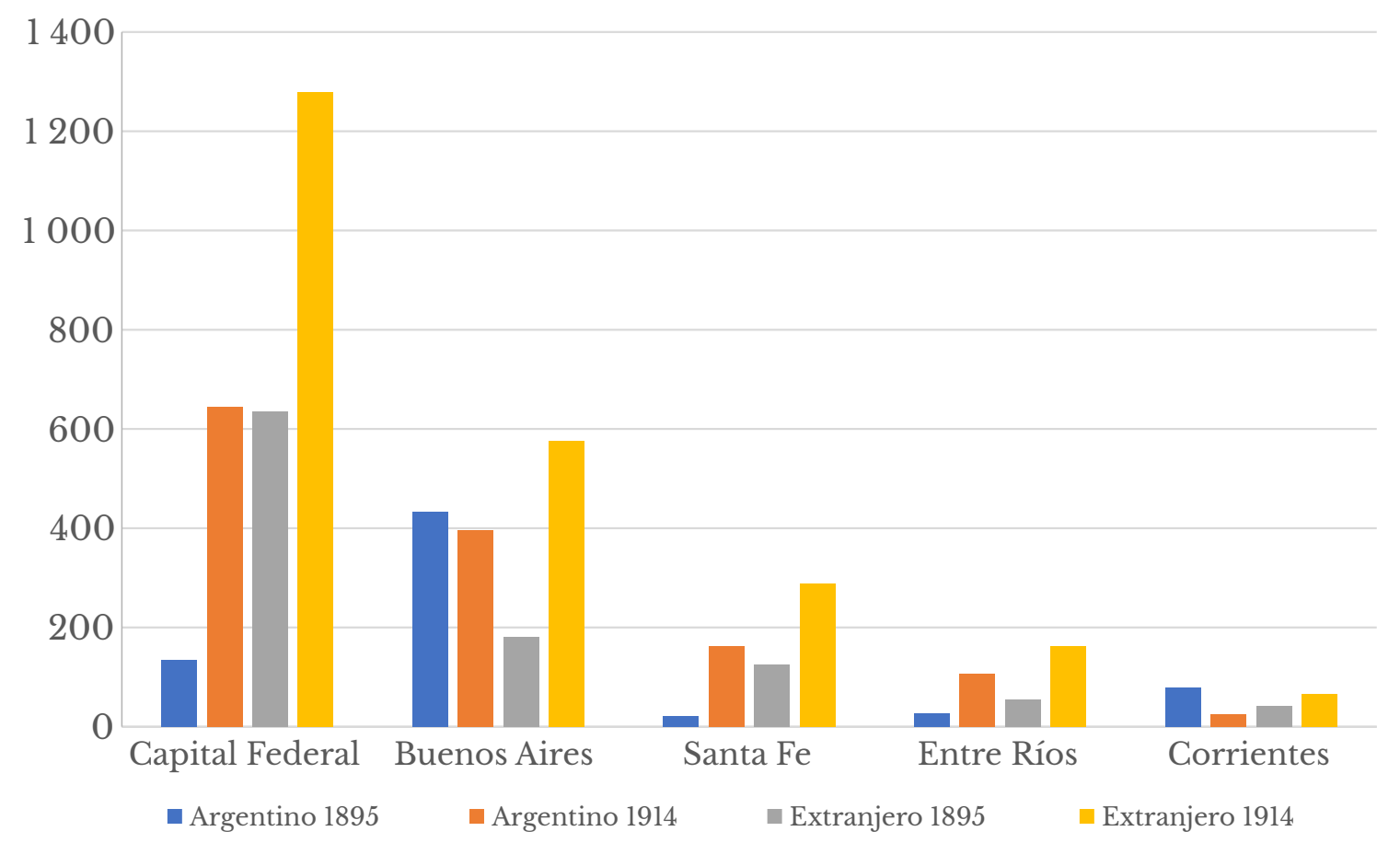

Fuentes: República Argentina (1895, 1914).

el año 1895, la cantidad registrada en el Censo bajo la categoría de músico, en la Capital Federal y en las provincias de Buenos Aires, Santa Fe, Entre Ríos y Corrientes era tan solo de 27 mujeres, de ellas 18 se encontraban en la ciudad de Buenos Aires. Para 1914 una abrumadora mayoría de las mujeres extranjeras se encuentra en la Capital, ascendiendo a 55, mientras que en el resto de las provincias señaladas solo eran cinco extranjeras.

Ahora bien, si buscamos ampliar nuestra mirada sobre algunos números en relación con los músicos extranjeros, las fuentes de las que disponemos son escasas, por lo cual el panorama para reconstruir una imagen acabada de ese grupo ocupacional es poco alentador. Una vía de acceso indirecta para su identificación es analizar la cantidad de músicos que arribaron al país. En ese sentido, una reconstrucción a partir de las listas de ingresos de los vapores de ultramar arroja que el porcentaje más importante de artistas y cantantes llegados a Argentina entre 1882 y 1920 eran italianos, le seguían los franceses y en tercer lugar los españoles (véase gráfica 4).

En el caso de los italianos arribados al puerto de Buenos Aires entre 1882 y 1920, 56 \% había embarcado en Génova, $14 \%$ provenía de Río de Janeiro y $13 \%$ de Santos (Brasil). A partir de la reconstrucción de los puertos de origen, de los avisos en la prensa y de las trayectorias de numerosos músicos, es posible identificar una ruta comercial entre Italia, Brasil y Argentina en la que participaban músicos, escenógrafos y empresarios teatrales (Ceva, 2020b). Para complementar esa imagen hemos recurrido a otras fuentes, en ese caso de índole más cualitativa, que también muestran ese mundo. 


\section{GRÁFICA 3. MÚSICOS EN ALGUNAS PROVINGIAS ARGENTINAS, SEGÚN NATIVO Y EXTRANJERO, 1895 Y 1914}

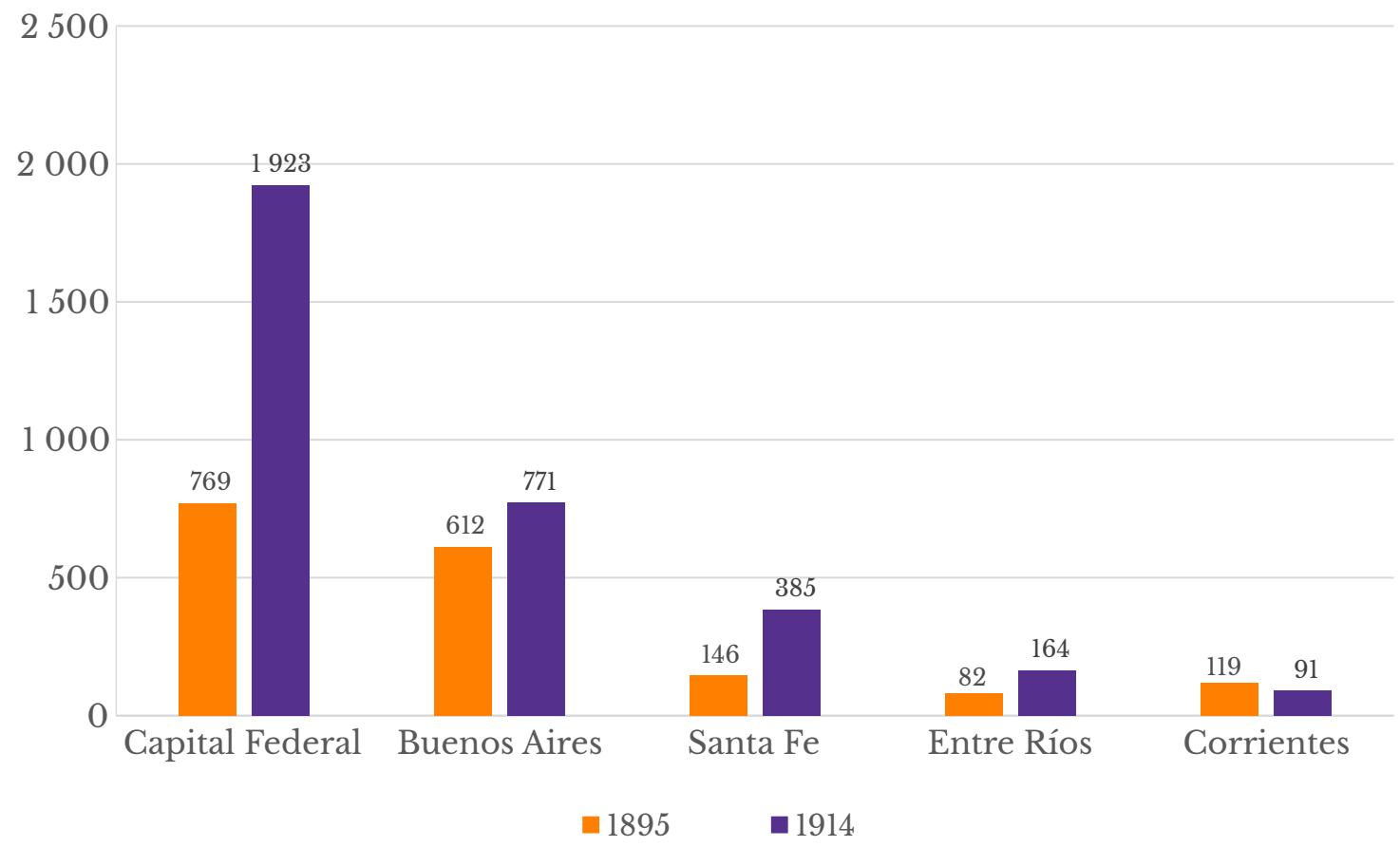

Fuentes: República Argentina (1895, 1914).

Algo más que los números

El crecimiento en el número de teatros y en los músicos hacia la primera década del siglo xx puede ser refrendado con fuentes de carácter cualitativo, por ejemplo, la prensa nacional y extranjera. El conocimiento de la circulación, la difusión y la penetración de los espectáculos musicales, nacionales y foráneos, a través de la prensa ha sido ampliamente estudiado, sobre todo para el caso italiano. ${ }^{13}$ Las revistas funcionaban como órganos culturales de parte de la comunidad italiana en Argentina, eran espacios en los cuales se plasmaban las disputas locales y era una caja de resonancia de los conflictos peninsulares.

En este caso, hemos utilizado La Patria degli Italiani y L'Operaio que eran, para fines del siglo XIX, dos de los tres periódicos más importantes en idioma extranjero. Esta prensa brindaba información y noticias de toda naturaleza, pero sobre todo contribuía a delinear y configurar un espacio destinado a valorizar y enfatizar el rol cultural que la presencia italiana tenía en las tierras argentinas y su importancia como difusores de su identidad. ${ }^{14}$ Esto se vinculaba también con el proceso, iniciado en la península durante la primera mitad del siglo xix, en el que la lírica se había convertido en una pieza fundamental para movilizar a la opinión pública. En ese proceso Giuseppe Verdi había contribuido a enaltecer la imagen de Italia en la escena internacional. Hacia el último cuar-

${ }^{13}$ Sobre la prensa italiana y su relación con la cultura, véase Weber (2016).

${ }^{14}$ Sobre la importancia de la cultura y de los referentes culturales italianos en Argentina, véase Devoto (2006). 


\section{GRÁFICA 4. PRINCIPALES NACIONALIDADES DE LOS ARTISTAS Y MÚSICOS LLEGADOS AL PUERTO DE BUENOS AIRES, EN VAPORES DE ULTRAMAR, ENTRE 1882 Y 1920}

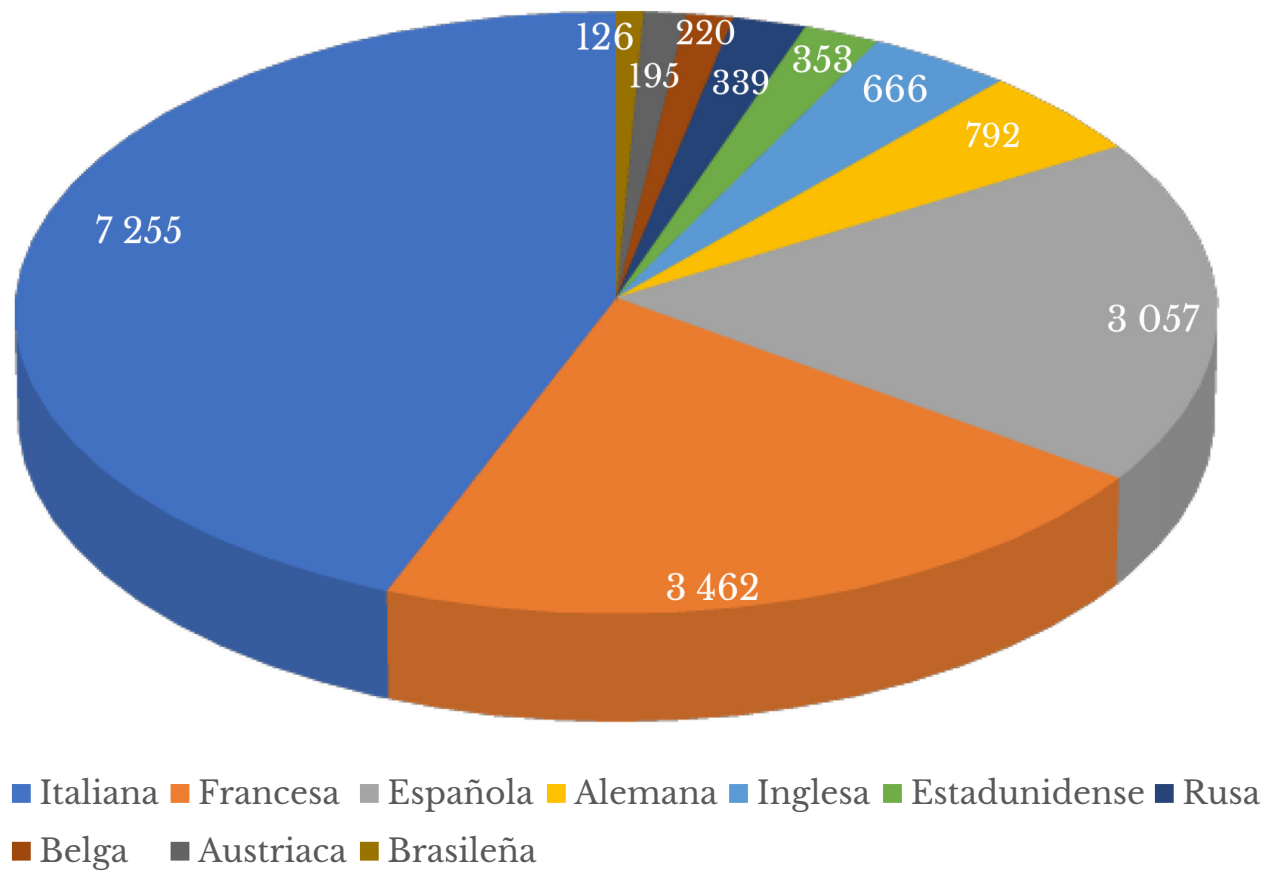

Fuente: elaboración propia con base en Centro de Estudios Migratorios Latinoamericanos (2011).

to del siglo xix, y con el acompañamiento de Manzoni -representante de la cultura italiana en el campo de las letras- se terminaría de dar forma a un lenguaje que los italianos tendían a considerar como la emanación de su personalidad nacional (Milza, 2006, p. 11). En ese sentido la ópera, Italia y patria se relacionaban y uno de los canales de esa difusión fueron las salas teatrales que comienzan a multiplicarse acompañadas por las sociedades de socorros mutuos. El crecimiento de los teatros se vio claramente respaldado por los capitales de las asociaciones mutuales (Bernasconi y Ceva, 2018, p. 182).

Hacia inicios del siglo xx los espectáculos en la capital nacional de Argentina se habían incrementado notablemente y la importancia de la ópera era destacada en las noticias, por ejemplo, La Patria degli Italiani, en agosto de 1908, señalaba sobre el Ópera: "Para hacerse una idea del lujo y esplendor de Buenos Aires es necesario acudir por unas noches a la ópera, el teatro de ópera de la ciudad en la 'calle' Corrientes, destinado a recibir a las mejores compañías de canto que anualmente llegan desde Italia, para realizar temporadas generalmente afortunadas y memorables" (p. 3, traducción de la autora).

Ese mismo año también se destaca por la inauguración del nuevo Colón. Numerosas voces resaltaron su importancia y su vínculo con músicos italianos. Cesarina Lupati (1910), cronista italiana, comenta: 
El teatro, en América, es también una de las mayores fuentes del río de oro. Buenos Aires tiene varios teatros, muchos, tal vez tantos como todas las demás ciudades argentinas, juntas. Los principales son la Ópera, que es la más aristocrática, y el Colón, de reciente construcción, que es el más lujoso y, en tamaño, el primer teatro del mundo. Los artistas italianos lo han consagrado y parece estar dedicado a los artistas italianos, ya que se suceden, con magníficos escritos (p. 76, traducción de la autora).

Según la información vertida en las memorias de la municipalidad de Buenos Aires, la actividad teatral para 1908 también da muestra de la fuerte presencia de la lírica italiana en los teatros de la capital, aunque solo el Colón tiene a la ópera como exclusividad. Los otros con presentaciones de ópera italiana eran el Ópera, El Coliseo Argentino, el Odeón, el Victoria, el Nacional y el Marconi (Benzecry, 2014, p. 196).

El esplendor de 1908 se repite para 1910; según nuestras fuentes, en ese año, en la Ciudad de Buenos Aires había 112 cantantes. Esta información cuantitativa se complementa con lo señalado por numerosos autores sobre el auge de la ópera para el momento del Centenario de la Revolución de Mayo: ${ }^{15}$ en 1910 existieron en la ciudad de Buenos Aires 532 funciones de 53 óperas distintas (La Nación, 2010). Una estadística publicada en La Patria degli Italiani, del 11 de enero de 1911 señalaba que: "seiscientas representaciones de ópera en un año es posiblemente, una cantidad rara vez alcanzada en otra ciudad del mundo. [...] en total 53 óperas subieron al escenario en los teatros porteños pertenecientes a 27 autores, de los cuales 15 eran italianos, 7 franceses, 3 alemanes, 1 brasileño y 1 ruso". ${ }^{16}$

Según Dillon y Sala (1997, p. 117) la lista de los compositores indicaba este orden: Verdi (154), Puccini (68), Mascagni (44), etcétera. También durante el año 1910, quince de las 83 representaciones llevadas a cabo en el Colón se identificaron como extraordinarias, ocho de ellas protagonizadas por el barítono italiano Titta Ruffo. ${ }^{17}$ Este artista cantó en 27 funciones. ${ }^{18}$

Por otro lado, es cierto que existía un circuito de grandes salas, pero existían también circuitos paralelos y simultáneos, por ejemplo, era habitual que los cantantes llegaran a la Capital Federal, brindaran funciones en el Colón y luego partieran hacia el interior del país para presentarse en el teatro El Círculo de Rosario, o en el Aguiar de San Nicolás (Ceva, 2020a, p. 367). Antes de su llegada se reproducían los avisos en los periódicos locales anunciando el arribo de las compañías, la composición y las presentaciones que se harían. Esos anuncios se realizaban en la prensa nacional, pero también en la prensa de las ciudades por las que transitaban. Asimismo, durante su permanencia en el país los artistas europeos, además de dar funciones en los más grandes teatros, realizaban presentaciones en otros lugares. Como relata Pedro Rivero (2000, p. 103), estos reconocidos artistas brindaban conciertos en la Sociedad Sportiva, en el Palacio Mihanovich, en la Unione Operai Italiani, en el Círculo Italiano, incluso en la dársena norte del puerto donde es-

${ }^{15}$ El 25 de mayo de 1910 se festejaron los 100 años de la dimisión del virrey Cisneros y el establecimiento de la Primera Junta de Gobierno.

${ }^{16}$ La Patria degli Italiani, 11 de enero de 1911, en Dillon y Sala (1997, p. 117).

17 Titta Ruffo había nacido en 1877 en Pisa, con 20 años estudió en la Academia de Santa Cecilia, en Roma. Sin finalizar sus estudios se mudó a Milán. Llegó a Sudamérica en 1900 al teatro Municipal de Santiago de Chile. Véase gacetilla Gran Teatro del Liceo, núms. 15-16; Chile, 1916. En el teatro Colón de Buenos Aires intervino en las temporadas líricas de 1902, 1908, 1909, 1910, 1911, 1915, 1916, 1926, 1928, 1931, en Rivero (2000, p. 96).

${ }^{18}$ La Nación, 29 de noviembre de 1911, en Rivero (2000, p. 94). 
taba fondeado el buque Principessa Mafalda. Posiblemente, uno de los motivos de su presencia allí era la de complementar sus ingresos, pero también su llegada a esos otros lugares les otorgaba reputación y fama entre sus connacionales.

El interés por el teatro también es evidente en el crecimiento del público, por ejemplo, durante el mes de marzo de 1888 el total de espectadores que asistieron al conjunto de las salas de la ciudad llegaba a 116141 espectadores, un promedio elevado para un periodo considerado fuera de temporada (Dillon y Salas, 1997, p. 3) y sobre todo si se recuerda que para 1887 la ciudad de Buenos Aires contaba con 433375 habitantes (González, 2015, p. 38). Asimismo, se ha señalado que entre 1900 y 1910 los espectadores que concurrieron a salas de teatros -aunque no solo de ópera- en la ciudad de Buenos Aires crecieron de 1500 000, en 1900, a 6600000 en 1910, mientras que la población creció de 663000 habitantes (según el censo de 1895) a 1300000 habitantes (Dubatti, 2017, p. 200). Además, como ha señalado Ricardo Passolini, hacia fines de siglo la ópera y la opereta se habían convertido en un género teatral de consumo masivo. Una muestra de ello es que entre 1894 y 1905, el número total de asistencias registradas a los espectáculos teatrales se había incrementado casi una vez y media, y la concurrencia a la ópera y la opereta cerca de dos. Dentro del consumo teatral se incluían también la zarzuela, las comedias y los dramas en italiano o francés, los sainetes de origen español y, hacia principios del siglo, los dramas de autores argentinos (Pasolini, 1999, pp. 228-253).

Es importante señalar que, a nivel nacional, un papel fundamental para el crecimiento de espectadores fue la aparición de pequeñas salas teatrales en el interior del país que apoyadas y construidas por las asociaciones de socorros mutuos sirvieron de espacios de sociabilización y de encuentros culturales. Algunos autores han mostrado que el público estaba formado por la elite, nativa y extranjera, ${ }^{19}$ e incluso se ha señalado el impacto que tuvo el respaldo económico de los italianos sobre algunos teatros en particular. ${ }^{20}$ De hecho, el público que consumía ópera era muy heterogéneo. En el interior, aún más que en la capital su construcción significaba una muestra de su crecimiento. Para el caso italiano, Carlotta Sorba (2001, p. 62) señala que el auge de la edilicia teatral puede tener dos sentidos distintos: por un lado, la difusión capilar sobre el territorio de los teatros públicos, como monumentos en los cuales es llamada la colectividad entera y, por otro, el surgimiento de un mundo más variado y cambiante de salas teatrales, de iniciativa privada y con funciones más propiamente comerciales.

En el caso argentino, hacia finales del siglo xix e inicios del xx, con el crecimiento de las ciudades y de la inmigración las nuevas poblaciones urbanas ofrecieron un público ávido de pasatiempo. Para satisfacer esta demanda se utilizaron antiguos espacios y se construyeron nuevos, entre ellos los teatros. Algunos financiados por los gobiernos locales o nacionales y otros en manos de privados, sobre todo las asociaciones mutuales de extranjeros, fueron las encargadas de gestionar la llegada de nuevos productos culturales. Asentados la mayoría de ellos en la zona del litoral rioplatense, zona de fuerte impacto migratorio, se caracterizaban por la diversidad de su tamaño, de su capital y por los espectáculos que ofrecen. Muy pocos se identifican como de ópera, la mayoría deben incluir no solo opereta y zarzuela en su oferta, sino también circo y acrobacia, único modo de sobrevivir a los vaivenes de un mercado limitado. Esa combinación de una mercancía global, como la ópera y opereta, con una local, circo y atracciones varias, permitía hacer el negocio más

${ }^{19}$ Sobre la interacción y relación entre la elite nativa y los dirigentes de las asociaciones de socorros mutuos italianas y los motivos de dicha relación, véanse Bertoni (2001) y Devoto (2006).

${ }^{20}$ Sobre la importancia de empresarios y asociaciones italianas en la construcción y gestión de salas teatrales, véase Ceva (2018). 
rentable. Asimismo, el aprovechamiento de las temporadas invertidas, con el continente europeo y -como se verá en el siguiente apartado- la existencia de redes de mediadores, encargados de formar mercado a través de una aceitada circulación de información, hicieron posible la consolidación de una industria teatral operística en Argentina.

\section{ESTRUCTURAS INFORMALES Y FORMALES EN LA GESTIÓN DEL MERCADO MUSICAL}

\section{Intermediarios, asociaciones y sociedades}

El mercado teatral, y el de ópera en particular, era amplio, cambiante y fluido. Puesto que, si bien podría significar una estructura rígida y con normas internas, en esa rigidez existían redes conformadas de individuos que compartían trayectorias laborales, ${ }^{21}$ y en algunos casos familiares y amicales, muy extensas y con personajes que circulaban entre los diversos ambientes, no solo espaciales, sino también sociales (Ceva, 2020b, p. 367). Son redes cambiantes en las que se pueden observar estructuras que se consolidan a partir de inicios del siglo xx y que se han definido en la interacción continua entre Italia y Argentina y también entre la ciudad de Buenos Aires y el interior de Argentina.

Claramente si vinculamos los datos espaciales y ocupacionales de este mercado de trabajo, una primera imagen resultante es la de un centro -Capital Federal- que irradia progreso por ser capital de la república, pero también por ser el lugar físico que permitía un contacto más directo con la cultura europea que se trataba de encarnar. Ciertamente, como ha demostrado Benzecry (2014, p. 181), la plaza de Buenos Aires se encontraba desde muy tempranamente vinculada o en sintonía con las más renombradas salas operísticas mundiales, por ejemplo, con la Scala de Milán o la Ópera de París. Una muestra de ello era la cercanía temporal entre los estrenos de algunas piezas y su presentación, a los escasos meses, en Buenos Aires. ${ }^{22}$ Pero si bien está claro que Buenos Aires era un centro de producción cultural que atraía y absorbía recursos, iniciativas y talentos, los concentraba y generaba la sinergia que surgía de ese contacto, el interior, como ya se señaló, no se encontraba ajeno a esta expansión y penetración territorial de teatros y de artistas; eso era posible por la existencia de estructuras formales de difusión, pero sobre todo por la combinación de aquellas con los mecanismos informales.

En ese mundo teatral, y también como forma de atemperar los altibajos de una profesión inestable e incierta, se recurría a un empresario. Este asumía diversas funciones y era indispensable para la organización de la tournée. El empresario teatral hacía las veces de mediador entre el artista, el público y otros actores del campo artístico. Este intermediario desempeñaba varios papeles, podía ser inversionista, socio, productor, operador, contratista, agente, etcétera. Para el caso italiano, Cavaglieri (2012) asevera que durante los últimos años del siglo xIX se produjeron numerosas transformaciones que involucraron la producción y distribución de los espectáculos, desde la Unificación de Italia hasta los comienzos del fascismo. Uno de los principales cambios fue el debilitamiento de las formas tradicionales de diversión y de los sistemas de producción en los

${ }^{21}$ Sobre la importancia de las trayectorias individuales laborales en el mercado de trabajo, véase Levi (1990).

22 Por ejemplo, Pagliacci se presenta en Buenos Aires el 28 de febrero de 1891 luego de unos pocos meses en que Ricordi la presenta en Italia; La Boheme se estrena en Argentina cuatro meses después de su presentación en Torino y Madame Butterfly llega a Buenos Aires dos meses después de su revisión final en Brescia, en mayo de 1904 (Benzecry, 2014, p. 181). 
que estaba basada y el surgimiento de las primeras asociaciones teatrales. ${ }^{23}$ Así, para el desarrollo de la actividad, una figura central era el empresario de ópera. Una de sus tareas era la organización, luego de la estación invernal europea, para partir hacia América, sobre todo hacia Argentina, Brasil, Uruguay y Chile (Giaccometti, 2013, p. 5).

La expansión internacional de la ópera se asentaba en dos cuestiones: 1) la económica: el mercado italiano había devenido insuficiente, y 2) la cultural: la ópera lírica era parte de un proceso de penetración de la cultura italiana en los nuevos países, por ejemplo, en Argentina. Ello formaba parte de un movimiento cultural más amplio que incluía todas las artes. En el caso de Buenos Aires se encontraban artistas plásticos, críticos o literatos que abarcaban los nombres más diversos, desde Decoroso ${ }^{24}$ hasta Gennaro D’Andrea ${ }^{25}$ (Malosetti, 2011). Se entendía que a través del expansionismo italiano y la circulación de las artes se permeaba a las sociedades de América del sentimiento de italianidad en los emigrantes. La ópera representaba para algunos italianos una referencia para su identidad - real o imaginada-, para otros, los sectores en ascenso, los distinguía y les permitía legitimarse y legitimar la autoimagen de Italia en América (Devoto, 2018). En el caso de Argentina y de la lírica, Vicenzo Di Napoli ${ }^{26}$ (1906, p. 128) destaca que el arte lírico en la América de fin de siglo tiene puntos luminosos en su horizonte, como Ettore Panizza; ${ }^{27}$ Ferruccio Cattelani ${ }^{28}$ y Elmérico Fracassi. ${ }^{29}$ Estos referentes, junto a otros músicos y compositores, formaban parte del conjunto de mediadores ${ }^{30}$ culturales de la Argentina de finales del siglo xix e inicios del xx.

En parte, era producto de un éxodo incentivado por el gobierno italiano de fines del siglo XIX, que tendía a concebir en términos de hegemonía política la emigración con el fin de formar una nueva y más grande Italia, y convertirlo en el objetivo de un expansionismo comercial e industrial pero también cultural (Paoletti, 2015, p. 16). Incluso la creación de la Societá Italiana del Teatro Lírico, ${ }^{31}$ en Italia en 1904, postulaba entre sus objetivos: "la nueva Sociedad, centrará alrededor de sí todo el gran movimiento cultural musical italiano, manteniendo el culto a la Ópera monumental de los grandes Maestros y aumentando el prestigio en el exterior de nuestro arte moderno" (Musica Nuova, 16 de febrero de 1904, p. 12, traducción de la autora).

${ }^{23}$ Estas nuevas formas de experimentación fueron estrategias para expandir el mercado teatral, los intentos de los organizadores teatrales de limitar el riesgo comercial y equilibrar la relación entre inversiones e ingresos en un momento en que los costos de producción tendían a aumentar también debido a la aparición de un nuevo capítulo de gastos: derechos de autor (Cavaglieri, 2012).

${ }^{24}$ Bonifanti Decoroso, pintor nacido en la Liguria, Italia, el 24 de junio de 1860, estudió en la Academia Albertina de Turín y llegó a Argentina en 1884.

25 Gennaro D’Andrea (1860-1937) era un músico italiano, nació en Nápoles y falleció en Buenos Aires.

${ }^{26}$ Vincenzo Di Napoli, escritor y periodista italiano, llegó a Argentina en 1896 con una compañía dialectal italiana traída por Cesare Ciacchi.

${ }^{27}$ Ettore Panizza nació en Buenos Aires en 1875, desarrolló una prolífica vida musical internacional, falleció en Milán en 1967.

${ }^{28}$ Ferruccio Cattelani (1867-1932) era un violinista y director de orquesta italiano que se radicó en Buenos Aires en 1897.

${ }^{29}$ Elmérico Fracassi, músico, nació en Campobasso, Italia, en 1874 y falleció en Argentina en 1930. En 1901 fundó el conservatorio que lleva su nombre.

${ }^{30}$ Sobre el papel de los mediadores en la movilidad, ajuste y adaptación, véase Ceva (2005).

${ }^{31}$ La Societá Italiana del Teatro Lírico fue una iniciativa de creación de una asociación anónima con el fin de mejorar el desarrollo del teatro lírico en Italia y en el exterior (Musica Nuova, 16 de febrero de 1904, p. 12). 
Esto no era nuevo. El sistema de ópera italiana tenía también una fuerte dimensión internacional, consolidada plenamente en el curso del ochocientos (Sorba, 2001, p. 14). Desde los años 1870 el mercado sudamericano era atractivo, aunque no era todavía un mercado de exportación directa de la ópera italiana, ya que habría que esperar algunos años para presenciar el auge teatral lírico (Rosselli, 1992, p. 161).

De hecho, rápidamente se percibe, para el caso argentino, un primer periodo, antes de 1900, en el cual se pueden identificar dos o tres empresarios destacados. Uno de ellos era Angelo Ferrari, quien desde 1856 y por 40 años había residido en Buenos Aires y representaba "la historia del arte lírico en la República Argentina” (Di Napoli, 1896), y el otro era Cesare Ciacchi. Sobre él se decía: "el suyo no es simplemente el nombre de un empresario, empresarios existen muchos, durante veinte años ha representado un nombre seriamente asociado a la educación artística sudamericana; y el crítico competente tiene el deber de [...] darle el lugar que se merece en la galería de los defensores de nuestra formación artística” (Di Napoli, 1896, traducción de la autora).

Ciacchi había nacido en el seno de una familia noble florentina (Il Teatro Illustrato, 1908, p. 9), y durante sus primeros años había tenido una breve carrera político-administrativa como jefe de gabinete de la Comuna de Florencia, bajo el gobierno de Bettino Ricasoli, ${ }^{32}$ sin embargo, por algunos problemas familiares, ${ }^{33}$ había decidido partir hacia América. Cuando llegó a Buenos Aires parece no haber encontrado lo que esperaba:

Él quería ser en tierra de ultramar el centinela vigilante de todo el arte contemporáneo, quería convertirse en el líder y revelador de todos los grandes artistas no solo en Italia, sino en Europa. Sin embargo, esta empresa no fue fácil para él, porque frente a él se situó otra figura de luchador atrevido, la de Angelo Ferrari que no estaba dispuesto a entregarlo fácilmente y dejarle el campo libre. Y entonces entre estos dos hombres estalló una pelea violenta, muy encarnizada en la que los dos mostraron una tenacidad y vigor que asombró no solo a los ciudadanos de la Capital, sino a los propios artistas que sacaron gloria y ganancias crecientes de esa rivalidad [...] la pelea tenía que ser mortal o terminar en una conciliación, y fue en esta última dirección (Il Teatro Illustrato, 1908, p. 10, traducción de la autora).

El mercado operístico italiano-argentino de fin de siglo se encontraba atravesado por grandes disputas en torno a ocupar una de las principales plazas sudamericanas. ${ }^{34}$ Angelo Ferrari y Cesare Ciacchi fueron los exponentes de esa lucha. Ambos italianos y ambos con fuertes vínculos en la madre patria se enfrentaron no solo en la arena cultural, sino que su disputa transitó los pasillos de los tribunales y dicho enfrentamiento es uno de los antecedentes de la ley de derechos de autor en Argentina.

\footnotetext{
${ }^{32}$ Bettino Ricasoli fue un político italiano, alcalde de Florencia entre 1848 y 1849 . Florencia es una ciudad situada en el norte de la región central de Italia, cuna del movimiento renacentista durante la mitad del siglo XIV.

${ }^{33}$ Lamentablemente desconocemos los motivos familiares de su partida hacia América.

${ }^{34}$ Para un exhaustivo desarrollo sobre la red de empresarios europeos en Sudamérica, véase Paoletti (2020).
} 


\section{¿Lucha mortal o conciliación? El caso Ferrari vs. Ciacchi}

En 1888 Ciacchi fue tapa en la prensa italiana y argentina por la representación en Argentina de la obra Otello de Verdi. Es interesante reparar en el conflicto porque expone gran parte de los problemas que planteaba el mercado teatral del periodo. A continuación, reproducimos algunas de las opiniones que se vertían sobre dicho proceso.

En la prensa Asmodeo, en una nota titulada "Ciaccheide" se señalaba que "La pregunta que ha surgido a propósito del Otello falso, falsificado o robado de Verdi, que el empresario Ciacchi va a representar en los teatros de Sudamérica, en lugar de calmarse, sigue creciendo cada vez más, y el estigma de la culpa que se inflige al especulador deshonesto es unánime" (Asmodeo: Monitore Settimanale dei Teatri, 1888, p. 6, traducción de la autora).

La discusión también reflejó en la prensa de Milán, Génova y Roma: "Espero que, en América del Sur, donde la obra del ingenio extranjero no está garantizada por leyes especiales contra especuladores, la propiedad sea protegida -protegida artística y financieramente- por el presidente de la República Argentina. Quien sin duda sabrá hacer valer los sacrosantos derechos de Verdi, ciudadano de todo el mundo intelectual" (Asmodeo: Monitore Settimanale dei Teatri, 1888, p. 6, traducción de la autora).

Los elementos que se desprenden del conflicto son varios: $a$ ) la ausencia o falta de legislación en torno a los derechos de autor; $b$ ) el papel que el poder ejecutivo de la nación podía cumplir en la esfera cultural, $\mathrm{y} c$ ) la figura de Verdi en el mundo intelectual del momento. La disputa involucró no solo a los empresarios, sino también a los editores, ya que la acusación tuvo la respuesta de Della Cella, editor del periódico Secolo XIX, y corresponsal de La Patria Italiana de Buenos Aires, cuando el 23 de enero de 1888 enviaba una nota remarcando que lo hacía para sentar su postura sobre un tema candente en el círculo teatral y musical y afirmaba, en primer lugar, que la empresa de Ferrari era la única concesionaria autorizada, por un contrato con la casa Ricordi de Milán, para reproducir con derecho durante el año 1888, en cualquier teatro de América del Sur, el último trabajo de Verdi (Asmodeo: Monitore Settimanale dei Teatri, 1888, p. 6), y sobre Ciacchi decía: "un individuo, al que no podría dar decentemente el título de empresario teatral, había establecido e incluso anunciado urbi et orbi que él, propiamente él, hubiera dejado que el público de un determinado teatro de la ciudad disfrutara las melodías de Otello" (Asmodeo: Monitore Settimanale dei Teatri, 1888, p. 6, traducción de la autora).

Claramente, señala Della Cella, es imposible que Ciacchi pusiera en escena el verdadero Otello ya que todos los derechos eran de Ferrari, de modo que este empresario llevaría a cabo una profanación estafando al público. Es decir, el problema no era solo una cuestión de violación del derecho de reproducción respaldado por un contrato, sino de la estafa al público y, peor aún, del menoscabo del autor en su creación. Por supuesto que del lado de Ferrari también existía un daño económico. A ello se agregaba algo no menor:

La prensa y el público porteño le darán tal acogida, que le enseñará de una vez por todas cómo en la Argentina no se permite traicionar la verdad, ofender la fama y el nombre del más ilustre maestro vivo, y arrojar la burla a una de las más gigantescas extracciones de ese arte, que está amparado por un sentido moral y un gusto estético incluso más allá de las fronteras de la patria (Asmodeo: Monitore Settimanale dei Teatri, 1888 , p. 6 , traducción de la autora). 
Ello daba cuenta de un público conocedor de las piezas. Della Cella agregaría una nota posterior haciendo referencia a Ciacchi como "ladrón o instigador" (Asmodeo: Monitore Settimanale dei Teatri, 1888, p. 6, traducción de la autora). Por su parte, en Asmodeo se señalaba que "la lección es dura y costosa; pero el Ciacchi, con su incontinencia de mendigo borracho, se la tiene bien merecida" (Asmodeo: Monitore Settimanale dei Teatri, 1888, p. 6, traducción de la autora).

Ahora bien, más allá de las numerosas notas que alzan sus voces por el derecho que le corresponde a Ferrari en su exclusividad, la prensa también señala que Ciacchi podría ser acusado solo de falsificación de propiedad intelectual y solo cuando retornara a suelo italiano, ya que la legislación italiana así lo permitía, pero ello no sería posible en Argentina. Es decir, el conflicto también muestra la precariedad de las relaciones contractuales en el país sudamericano. La pelea por el mercado argentino fue tan fuerte que incluso traspasó el ámbito comercial y llegó a la justicia. ${ }^{35}$

En la causa pueden identificarse los elementos de choque que caracterizaban al mercado operístico del momento. En los alegatos se insiste con la distancia entre la legislación italiana, que respalda los derechos de propiedad intelectual dentro del territorio italiano, y la argentina que no solo no acepta los otorgados por aquella, sino que no cuenta con una nacional. También se enfatiza en los mecanismos a través de los cuales se calcula la ganancia que corresponde a los empresarios y el perjuicio que ocasiona la falta de transparencia en el cómputo del borderó. El expediente tiene marchas y contramarchas e involucra no solo a Ferrari y a Ciacchi, sino también a la Casa Ricordi (Quesada, 1904). Sin embargo, luego de varios años de litigio, ambos empresarios terminaron en un acuerdo e incluso formaron una única compañía dirigida por Marino Mancinelli.

Durante el transcurso de la disputa y con el devenir de los años, Cesare Ciacchi fue posicionándose en el mercado latinoamericano, de hecho, para 1900, La Gazzetta Teatrale Italiana reseñaba: "felicitamos a Cesare Ciacchi por las pruebas de cariño y estima recibidas, que reproducimos, seguros de que complacerá a los artistas y amigos que lo conocen" (Gazzetta Teatrale Italiana: Asmodeo, 1900 , p. 1, traducción de la autora).

En pocos años Cesare Ciacchi contaba con una amplia red de relaciones en Italia y en Argentina. Era primo de Luigi Ducci, empresario en las mayores plazas de Chile, Brasil, Bolivia y Perú ya desde fines de los años ochenta del siglo xix (Paoletti, 2015, p. 28). La compañía de Ciacchi era importante, estaba compuesta por 203 personas, de las cuales 72 eran profesores de orquesta que arribaban de Milán, 58 coristas, 20 bailarinas y 24 músicos de bandas. Entre ellos se encontraba Emma Carelli, esposa de Walter Mocchi, ${ }^{36}$ quien posteriormente formara parte de la Sociedad Teatral. Además, del vínculo entre ellos hay que sumar al padre de Carelli, quien también había sido músico, y a su hermano Enrico, escenógrafo. Es decir, esposos, primos y cuñados se encontraban enlazados en la actividad musical. La característica de este mercado de trabajo supone un proceso en el que estaba involucrada toda la familia. Los diferentes miembros participaban en la toma de las decisiones sobre la migración y sobre el ingreso al trabajo, eso implicaba el acuerdo de todos los actores, los cuales a su vez buscaban o trataban de maximizar algún tipo de beneficio en la cooperación, o en la competencia con los otros. ${ }^{37}$

\footnotetext{
35 Sobre el tema de la propiedad intelectual y la causa Ferrari versus Ciacchi, véase Quesada (1904).

${ }^{36}$ Sobre la figura de Walter Mocchi, véase Paoletti (2015).

${ }^{37}$ La importancia de las relaciones personales familiares en los procesos migratorios, en el ajuste a las nuevas sociedades de recepción y en el ingreso al mercado laboral son temas ampliamente desarrollados por los estudios migratorios en general, y en particular para el caso argentino. Para una síntesis, véase Devoto y Otero (2003).
} 
Dentro de este esquema el proceso de adquisición y difusión de la información obtenida se convertía en central. Estas mediaciones en sus inicios fueron informales y con los años se instrumentaron a través de la creación de una estructura formal: la sociedad teatral. Esa nueva gestión también incorporaba muy fuertemente la publicidad y el marketing instrumentados a partir de la creación del periódico Il Teatro Illustrato, y de la difusión de las giras en los principales diarios del momento, todo lo cual elevaba los costos, pero, por otro lado, potenciaba los espectáculos y la llegada a un público más amplio. Es interesante destacar que al menos durante estos primeros años los artistas aparecen relacionados a más de una compañía; mantienen intensos vínculos entre los cantantes y circulan en escenarios de diversa naturaleza (Ceva, 2020b, p. 360). Los mediadores viajaban constantemente entre Europa y América y ofrecían giras de las compañías que se armaban y desarmaban para llegar a Sudamérica. Iniciado el siglo xx esas compañías se hicieron más grandes, estables y profesionales. Para 1908 había 41 compañías, 18 de ellas eran italianas, y solo tres $^{38}$ pervivirán hasta el periodo 1924-1927, momento en el cual en total aparecen registradas 33. ${ }^{39}$ Claro está que el mercado musical, al igual que muchos otros de la Argentina de entre siglos, se caracterizaba por la inestabilidad, por la fusión o reabsorción por parte de algunas compañías de pequeños emprendimientos individuales.

Con el nuevo siglo y con los cambios ya avanzados en el viejo continente, el sistema tradicional se fue modificando y su aparición fue un tipo de asociación nuevo. En ese segundo momento se crea la Societá Teatrale Italo-Argentina, en 1907, luego transformada en otra sociedad, La Teatral, gestionada exclusivamente por Walter Mocchi. ${ }^{40}$ La Teatral tenía bajo su control los teatros el Constanzi de Roma, el Coliseo de Buenos Aires, el Municipal de Río de Janeiro, el de São Paulo, el Municipal de Santiago de Chile, el Solís de Montevideo y la Ópera de Rosario, entre otros; además contaba con la agencia italo-sudamericana de Milán y también con las compañías de operetas Mechetti y Caramba (Coli, 2016, p. 186). A los pocos años se había creado un verdadero mercado interoceánico y la Societá Teatrale Italo-Argentina y la Societá Teatrale Internazionale ${ }^{41}$ habían sumado nuevas salas teatrales: el teatro Argentina, en la ciudad de Roma; El Regio en Torino; el Carlo Felice, en Génova; el Regio, en Parma y el Petruzzelli, en Bari. En Sudamérica, había incorporado en Buenos Aires los teatros Colón, Odeón, Avenida y Constitución; en la ciudad de Rosario el Colón y el Olimpo, y en Chile había sumado en la ciudad de Valparaíso al teatro Sócrates; en Concepción, el teatro Municipal y en Talca el Municipal (Giaccometti, 2013, p. 75) (véase gráfica 5).

La aparición de este tipo de estructura asociativa con una gestión más moderna tuvo consecuencias muy importantes para el mundo de la ópera. Entre las nuevas características se encontraban la creación de las asociaciones en forma de sociedades anónimas y el establecimiento de vínculos contractuales entre sociedades en Italia (Societá Teatrale Internazionale) y en Argentina (Societá Teatrale Italo-Argentina y La Teatral). La presencia de una agencia garantizaba los contratos a los artistas, y aseguraba a los empresarios la calidad y la cantidad de cantantes. Como contra parte la agencia recibía un porcentaje que variaba según el destino, si era en el interior de Italia ese porcentaje era de $5 \%$, hacia el exterior era de $6 \%$, y para América ascendía a $10 \%$. De hecho,

38 Compañía lírica italiana de Cavalli, Compañía lírica Marranti y Compañía lírica Mocchi.

39 Datos obtenidos del Anuario Teatral Argentino 1924-1927, Buenos Aires.

${ }^{40}$ Walter Mocchi fue uno de los más importantes empresarios teatrales de la Argentina del inicio del siglo xx.

${ }^{41}$ Con el fin de optimizar la circulación de las compañías entre Europa y Sudamérica y reducir los costos de mediación, el 24 de julio de 1908 Mocchi fundó en Roma la Società Teatrale Internazionale, véase Paoletti (2020, p. 11). 


\section{GRÁFICA 5. GRÁFICA 5. TEATROS CON REPRESENTACIÓN GENERAL DE LA SOCIETÁ TEATRALE ITALO-ARGENTINA (1907-1916)}

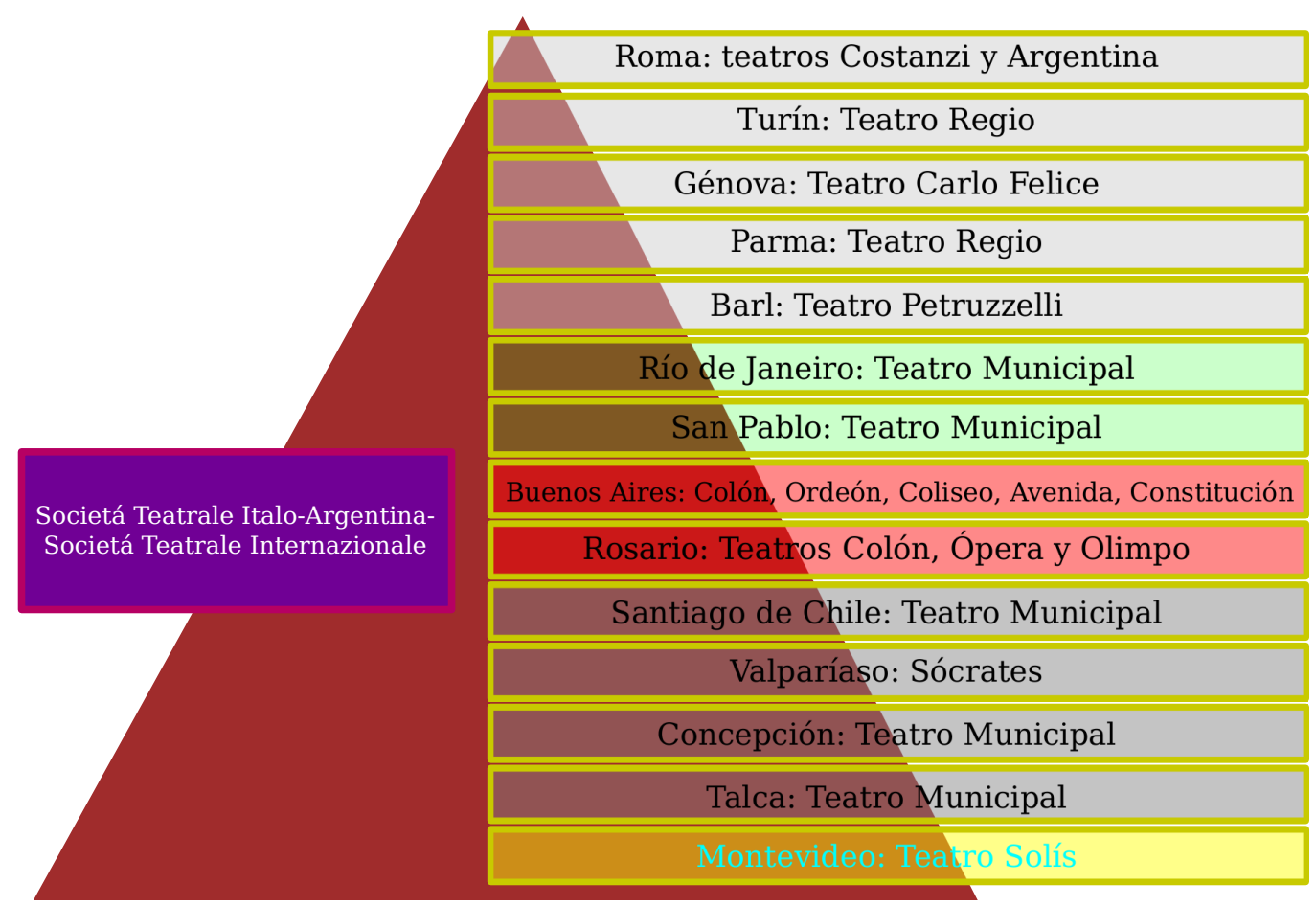

Nota: cada color identifica a un país diferente.

Fuentes: Coli (2016), Giaccometti (2013) y Paoletti (2015).

en el origen de la Societá Teatrale Italo-Argentina se indicaba que se fundaba para transformar la especulación teatral, convertirla en una verdadera industria, guiada por órganos capitalistas y con criterios puramente comerciales y artísticos (Paoletti, 2015, p. 29).

Una de las principales interrogantes es cómo fue el tipo de itinerarios profesionales que desarrollaron los artistas bajo el nuevo contexto organizativo. ${ }^{42}$ Para 1910 los empresarios de Rosario eran los mismos que organizaban las temporadas del Colón, Coliseo y Politeama (Benzecry, 2014, p. 182). En ese sentido, la inserción de los artistas en diferentes circuitos musicales dependía de su formación y de las redes de relaciones, pero también de su vínculo con estructuras formales de comercialización. Durante este periodo, que podría llamarse de transición, se observa que los mismos mediadores que hasta fines del siglo xix habían realizado su gestión a título personal, a inicios del siglo xx oficializan su accionar a través de organizaciones más formales como lo fue la Societá Teatrale Italo-Argentina. Es difícil identificar la relación entre los circuitos, redes y estructuras formales como también el peso de cada uno de estos elementos en el contexto argentino, sobre todo, cuando la legislación no acompañaba el gran crecimiento teatral. De hecho, recién a finales de 1907 se constituyó en Argentina la sociedad de autores dramáticos y líricos.

${ }^{42}$ Sobre la reconstrucción de un itinerario profesional musical, véase Ceva (2020b). 
Al llegar el centenario, la estructura teatral argentina se había incrementado. Los cantantes habían aumentado al ritmo de la migración y los antiguos mediadores tradicionales habían devenido -solo algunos de ellos-, empresarios encuadrados en las nuevas sociedades teatrales transnacionales. Sin embargo, a pesar de las transformaciones en la estructura organizativa la presencia de agentes, arreglos, acuerdos y negociaciones dan cuenta de un mercado musical recorrido por vínculos personales, lo cual, sin duda, permite establecer cierta continuidad con las formas tradicionales de organización.

\section{ConClusión}

\section{La inmigración y la formación del mundo musical}

Las migraciones transatlánticas durante el periodo 1880-1920 implicaron el desplazamiento de millones de trabajadores, algunos de los cuales eran músicos y cantantes. Esa actividad estaba destinada a un mercado específico que requería de teatros, publicidad y difusión, normativa y sobre todo de un público o consumidores. En la Argentina aluvial y en pleno crecimiento esas condiciones eran posibles de alcanzarse.

A lo largo de este artículo se ha mostrado la expansión territorial de las salas teatrales, el número de cantantes y su origen y la consolidación de un mercado musical. La geografía teatral musical que surge de los datos obtenidos muestra un mercado conformado a partir de la participación de capitales privados (asociaciones de socorros mutuos, pequeños empresarios, mayoritariamente extranjeros) y capitales públicos (especialmente municipales). La intervención de ambos buscaba la construcción de espacios para la diversión y el ocio, pero también lugares de referencia simbólica para las sociedades locales. Si lo miramos desde la oferta cultural, la ópera era uno más entre todos los géneros que circulaban en la Argentina del cambio de siglo, también era un espacio en el cual se destacaba la presencia italiana. Existían circuitos variados y múltiples con artistas que se presentaban en teatros, en salas de reunión de las asociaciones mutuales y también en salones sociales.

En su dimensión comercial y en tanto inmerso en las lógicas del mercado, el teatro debía convertirse en un negocio tanto para los artistas como para los mediadores. Una forma de optimizar los beneficios fue el pasaje de una gestión tradicional a una más moderna organizada bajo la forma de una sociedad anónima y basada en la relación contractual con los artistas y apoyada en una fuerte difusión de las actividades y de los artistas.

Este nuevo tipo de gestión empresarial musical era la misma que se utilizaba en Italia y es otro de los ejemplos de transferencia de saberes que se producen entre ese país y Argentina. Es una forma de gestionar el mundo operístico que tiene una dimensión internacional, con rutas comerciales culturales propias y con mecanismos de información precisos, donde la figura del empresario es central para obtener el lugar físico y como difusores de las actividades de sus representados, a partir de la publicidad en la prensa internacional. ${ }^{43}$ Son empresarios que se encuentran en el tránsito de un modelo a otro, encarnan un cambio organizacional, aunque en muchos casos son los mismos empresarios que se mantienen a lo largo de las décadas, con la diferencia de que hacia el inicio del siglo xx aparecen encorsetados en estructuras administrativas formales. Esto no implica que muchas de sus prácticas de gestión se apoyaran en mecanismos informales de negociación.

${ }^{43}$ En este caso puntual no se ha profundizado en la importancia de la publicidad y en el papel de las revistas especializadas en promover a determinados cantantes. 
Contratos, publicidad y porcentajes de representación fueron los elementos que definieron al mercado musical de inicios del siglo xx. A pesar de que estos ya estaban en el fin del siglo xIx, a partir del nuevo siglo se encontraran enmarcados en una legislación específica, con porcentajes claramente estipulados y con una multiplicidad de revistas especializadas para publicitar sus actividades. En sintonía con la expansión y consolidación de otros mercados en el área musical, las decisiones empresariales, la complementación de las temporadas entre Sudamérica y Europa, la aceleración en las comunicaciones, la publicidad y marketing, y la profesionalización de las giras permitieron la consolidación de un mercado de consumo operístico.

\section{LISTA DE REFERENCIAS}

Asmodeo: Monitore Settimanale dei Teatri (1888). 16, 6-7.

Benzecry, C. (2014). An opera house for the "Paris of South America": Pathways to the institutionalization of high culture. Theory and Society, 43(2), 169-196. DoI: 10.1007/s11186-0149214-7

Bernasconi, A. (2012). Inmigración y música: la influencia de los extranjeros en la producción y el consumo de música. Argentina a fines del siglo xIx y principios del xx, artículo presentado en la sesión Migraciones ayer y hoy. Identidad y música. Presentado en el Congreso de la International Musicological Society, Roma.

Bernasconi, A. y Ceva, M. (2018). Sociedades de Socorros Mutuos y teatros. Un ensayo de perspectiva comparada a partir de los casos de Gualeguay y Zárate. En C. Elmir, M. Witt, y O. Truzzi (eds.), Imigração nas Américas: Estudos de história comparada (pp. 160-191). São Leopoldo: Oikos/Unisinos.

Bertoni, L. (2001). Patriotas, cosmopolitas y nacionalistas: la construcción de la nacionalidad argentina a fines del siglo XIX. Buenos Aires: Fondo de Cultura Económica.

Cavaglieri, L. (2008). Daniele Chiarella "L'impresario selvaggio": Questioni organizzative tra Otto e Novecento nei teatri a iniziativa privata. Torino: Edizioni ETS.

Cavaglieri, L. (2012). Trust teatrali e diritto d'autore, 1894-1910: La tentazione del monopolio. Corazzano: Titivillus.

Centro de Estudios Migratorios Latinoamericanos (2011). Listas de vapores arribados al puerto de Buenos Aires [Base de datos]. Buenos Aires: Autor.

Cetrángolo, A. (2015). Ópera, barcos y banderas: El melodrama y la migración en Argentina (18801920). Madrid: Biblioteca Nueva.

Ceva, M. (2005). Los mediadores religiosos en la inmigración de trabajadores friulanos a Villa Flandria. Studi Emigrazione, 42(159), 611-624.

Ceva, M. (2018). Mediadores culturales y prácticas sociales en la construcción del Teatro Coliseo de Zárate, Argentina. Anuario Tarea, 5, 78-99.

Ceva, M. (2019). Un politeama en la pampa gringa argentina (1852-1908) [Seminario]. Italia: Universitá Degli Studi di Padova.

Ceva, M. (2020a). Entre los carnavales y el teatro de ópera. Sociabilidades en una pequeña ciudad, Zárate, Argentina (1880-1930). Anuario del Instituto de Historia Argentina, 20(1), 1-15. DOI: $10.24215 / 2314257 \mathrm{Xe} 112$

Ceva, M. (2020b). Las aventuras de una soprano italiana en América del Sur. Adelina Agostinelli (1882-1954). Studi Emigrazione, 57(219), 351-369. 
Coli, J. (2016). O negócio da arte: As influências da gestão e organização italiana na ópera lírica em São Paulo. Opus, 22(2), 173-192. DoI: 10.20504/opus2016b2207

Devoto, F. (2003). Historia de la inmigración en la Argentina. Buenos Aires: Sudamericana.

Devoto, F. (2006). Historia de los italianos en la Argentina. Buenos Aires: Biblos.

Devoto, F. (2018). La ópera, el teatro, el criollismo. En torno al Fausto, de Estanislao del Campo, y sus contextos, Anuario Tarea, 5(5), 32-54.

Devoto, F. y Otero, H. (2003). Veinte años después: una lectura sobre el Crisol de razas, el pluralismo cultural y la historia nacional en la historiografía argentina. Estudios Migratorios Latinoamericanos, 17(50), 181-228.

Di Napoli, V. (1906). Il teatro e gli artisti italiani nell'Argentina, en Comitato della Camera Argentina di Commercio ed Arti, Gli Italiani nella Repubblica Argentina. Buenos Aires: Stabilimento Grafico della Compañía General de Fósforos.

Dillon, C. y Sala, J. (1997). El teatro musical en Buenos Aires: La ópera, la opereta, la zarzuela, la comedia musical. Buenos Aires: Arte Gaglianone.

Dubatti, J. (2017). Apuntes para una historia de la teatrología en la Argentina. Culture Teatrali, 26, 196-212.

Giaccometti, D. (2013). La figura dell'impresario musicale Walter Mocchi e la costruzione di un'industria operistica fra Italia e Sud America (Tesis de maestría). Universitá Ca Foscari, Italia.

González, H. (ed.) (2015). 125 años de la estadística porteña. Buenos Aires: Dirección General de Estadística y Censos.

Grementieri, F. y Shmidt, C. (2019). El diseño de teatros en el siglo XIx. La Ópera en tres espacios. En V. Druetta y M. Sciolla (eds.), Teatro del Libertador General San Martín. Puesta en valor y actualización tecnológica (pp. 17-20). Córdoba: Gobierno de la Provincia de Córdoba.

Levi, G. (1990). Carrières d'artisans et marché du travail à Turin (xviıe-Xıxe siècles). Annales ESC, 45(6), 1351-1364. DOI: 10.3406/ahess.1990.278913

Lupati, C. (1910). Vida argentina. Barcelona: Maucci.

Malosetti, L. (2011). Visual arts and opera, in Italy and Argentina at the beginning of the 20th century. Pío Collivadino's case [Istituto per lo Studio della Musica Latinoamericana]. Recuperado de http://www.imla.it/dvd2/data/uk/index.html

Milza, P. (2006). Verdi y su tiempo. Buenos Aires: El Ateneo.

Paoletti, M. (2015). Mascagni, Mocchi, Sonzogno. La Società Teatrale Internazionale (19081931) e i suoi protagonisti. Arti della Performance: Orizzonti e Culture, 4. Dor: 10.6092/UNIBO/AMSACTA/4235

Paoletti, M. (2020). La red de empresarios europeos en Buenos Aires (1880-1925). Algunas consideraciones preliminares. Revista Argentina de Musicología, 21(1), 51-76.

Pasolini, R. (1999). La ópera y el circo en el Buenos Aires de fin de siglo: consumos culturales y lenguajes sociales. En F. Devoto y M. Madero (eds.), Historia de la vida privada en Argentina, t. II. La Argentina plural, 1870-1930 (pp. 227-273). Buenos Aires: Taurus.

Quesada, E. (1904) La propiedad intelectual en el derecho argentino. Buenos Aires: J. Menéndez. República Argentina (1895). II Censo Nacional de Población (t. 3). Argentina: Taller Tipográfico República Argentina (1914). III Censo Nacional de Población (t. 2). Argentina: Talleres Gráficos. Rivero, P. (2000). La lírica en el Buenos Aires del Centenario. En A. Leiva (ed.), Los días del Centenario de Mayo (pp. 87-115). San Isidro: Academia de Ciencias y Artes de San Isidro.

Rosselli, J., (1992). Sull ali dorate. Il mondo musicale italiano dell ottocento. Bologna: Società editrice Il Mulino. 
Sorba, C., (2001). Teatri. L'Italia del melodrama nell 'ettà del risorgimento. Bologna: Il Mulino.

Thernstrom, S. (1964). Poverty and progress. Social mobility in a nineteenth century city. Cambridge: Harvard University Press.

Weber, I. (2016). Modelos de interacción de las culturas en las publicaciones artístico-culturales italianas de Buenos Aires (1890-1910) (Tesis de Doctorado). Universidad de Buenos Aires, Argentina.

Weber, I., Martinovich, L. y Camerata P. (2019) Presencia de compañías líricas italianas en los teatros del litoral argentino (1908-1910), presentado en II Workshop sobre Historia y Patrimonio. Universidad Nacional de General San Martín, Argentina.

\section{Hemerografía}

Anuario Teatral Argentino 1924-1927, Buenos Aires.

Gazzetta Teatrale Italiana: Asmodeo (1900), 1(34), 1.

Gran Teatro del Liceo, Santiago, Chile.

Il Teatro Illustrato, Milán, Italia.

La Nación, Buenos Aires, Argentina.

La Patria degli Italiani, Buenos Aires, Argentina.

Música Nuova, Milán, Italia.

Secolo XIX, Buenos Aires, Argentina. 